years at the Society has originated, directly or indirectly, from this Committee. The result has been, it is true, owing to our labours, a partial reform; but Physiology and Anatomy have been brought to a low ebb. There are to be no more physiologists as senior or junior secretaries; and medical squabbles, instead of being sifted and righted, are voted bores by the vulgar members of the Society, such as Mr. SHEepSHANK, at the public meetings. Let Lord Rosse and Mr. Grove look well to their underlings. In our next we may again refer to these matters.

\section{PETITION OF SURGEONS OF SUSSEX.}

To the Honourable the Commons \&c.

The humble petition of the undersigned members of the

Royal College of Surgeons residing at Worthing, Sussex,

Sheweth,-That the charter granted to the College of Sur. geons in 1843 , forms an insurmountable obstacle in the path of medical legislation, and that no attempt to adjust by Act of Farliament the difficulties of this subject, can be successful or satisfactory until the injustice perpetrated by that partial measure be done away with.

That the Colleges of Physicians and Surgeons, if rightly organized, are quite sufficient for the requirements of the profession in this country, and that the proposed creation of a new corporation for the enrolment of the general practitioners, is uncalled for by any necessity; and that such new institution would be alike injurious to the interests of the profession and the public, more particularly to the poorer class, as it would be their lot to be attended by a class of practitioners of an inferior grade and acquirements. That the parties who have undertaken to appear on the part of the general practitioners in the conferences which have led to the proposal of a new corporation, have no title whatever to be considered as representing the views and opinions of that great body of the profession.

Your petitioners therefore humbly pray, that as a prepara. tory step to any measure for the regulation of the medical profession, the provisions of the charter granted to the College of Surgeons in 1843, and the manner in which they were carried out, may undergo a searching investigation; and that your honourable house will be pleased to reject any bill concerning the medical profession, which shall tend in any way to perpetrate the injustice inflicted by the said charter upon the great body of the members of the College of Surgeons. Your petitioners believe, that had the College of Surgeons, in 1843 , raised all the members of a certain number of years standing - say fifteen or twenty years - to the fellowship, without a second examination, and allowed all the remainder who were members before 1843 to become fellows as they respectively arrived at that period of membership, also without further examination, such a course of proceeding would have given general satisfaction to the profession.

And your petitioners will ever pray \&c.

(Signed) Henry John Gore. John Holmes Perkx. Morgan Cuteane. Henry James Collet.

\section{Corresponaence.}

$$
\text { " Audi alteram partem." }
$$

\section{REMARKS SUGGESTED BY THE MIDWIFERY! CASE IN STAFFORDSHIRE. \\ To the Editor of The Laveet.}

Sir,--In your editorial remarks on the revolting case of William Harding Flint, in last week's LANCET, you very justly observe, that if he be a medical man "this case throws a great responsibility on the various examining bodies for their systematic neglect of midwifery examinations, and obstetric education in general."

As a case in point, I beg to call your attention to the fact, that in the second examination for the B.M. degree, the candidate must have conducted at least six labours !

Not doubting but that he may be fully qualified in the theoretical, what knowledge can he have in the practical department? Will he be able, by the experience of six labours, to distinguish the os uteri, setting aside altogether the immense numbe of complications and difficulties which occur in the practice of midwifery? There are eight different presentations of the head alone, besides presentations of the arm, breech, \&c. What fitness, moreover, will this qualified (?) tyro have to attend a case of placenta prævia?

When we hear of the young practitioner fumbling about the anus en route for the os uteri, (which has actually been the case,) trembling if he finds the funis coiled round the neck, and losing all presence of mind if a few coagula follow the placenta, we cannot wonder that under preternatural and difficult cases mistakes of the most revolting character should so frequently occur.

So long as the practical department of midwifery is thus neglected by the examining boards, so long must it continue the opprobrium of the profession.

Apropos of this subject, I may observe that the Society of Apothecaries are in the advance of their fellows in this respect, for the apprentice, during his five years' servitude, obtains a far better knowledge of obstetric practice than the learned M.B., with all his certificates, backed by his six cases.

This strange anomaly requires investigation, and I trust you will not let the opportunity pass without calling the attention of the profession to it.- Yours most respectfully,

St. Helen's, Lancashire, August, 1848.

An Apprentige.

\section{THE LATE INQUEST AT PORTSMOUTH.}

\section{To the Editor of The Lancet.}

SrR,-I regret not having seen in the last number of your able and useful serial some explanation afforded by Mr. Garrington of the extraordinary discrepancies that appeared in his testimony on the extraordinary case which occurred on Southsea Common. In the absence of such explanation, we are bound to take the evidence as it has been reported; and from a careful consideration of that evidence, coupled with the non-medical testimony given on that inquest, I will take the liberty of submitting a few observations. The case may be more conveniently divided into three parts-mysteries, mistakes, and catastrophe.

First, then, its mysteries:-A young woman, aged twentythree, said to be in delicate health, and of imbecile mind, is brought from a great distance to a lodging-house, by a lady, who leaves her there in charge, and under the care of a lodging-house keeper. She is far advanced in pregnancy, and the lady who leaves her informs the doctor and the lodging-house keeper that she is in her sixth or seventh month. On this information the doctor relies, and proposes to anticipate the labour by inducing it in this seventh month, with the ostensible motive of preserving the life both of mother and child. It does not appear whether the female was married or single; but she is committed to the care of entire strangers, being of weak body, of weaker mind, and advanced in a situation which, under ordinary, still more under such extraordinary circumstances, should constitute her an object of sympathy, attention, and care.

Secondly, the mistakes:-Instead, then, of a contracted pelvis, Mr. Garrington declares it to have been of the ordinary size, and well developed. Instead of being only in the seventh month of pregnancy, Mr. Garrington declares her to have arrived at the full period. Mr. Garrington further states that the os uteri was dilated to the size of a shilling: this-in the entire absence of pain, and during the short period of the hour when Dr. Stewart was with her, and introduced the stilette-is quite conclusive that the natural labour was approaching, if, indeed, it had not already commenced.

Lastly, the catastrophe:-On the Saturday morning-the close of the scene-it appears that Mrs. Webster was quite well, in her dressing-room, when Dr. Stewart and his partner arrived, at half-past ten $o^{\prime}$ clock, to induce the labour by artificial means, under the impression that she was then only in her seventh, instead of her ninth month of pregnancy. If the os uteri was dilated to the size of a shilling, could that dilatation have been accomplished by the stilette? If, as I ap. prehend, that was impossible, could not the dilatation have been cautiously and gradually extended without the introduc. tion of this instrument? The stilette, however, is introduced, a puncture is made, sudden faintness supervenes, and death follows. An inquest is held, a post-mortem examination takes place, an artery immediately contiguous to the part to be punctured is absolutely opened, another opening is found in the peritonæum, and yet the uterus and vagina are said to have been discovered in their full integrity! I have but one question to put: will any surgeon name a disease of an artery that terminates by a slight opening of its coats, without their previous distention into the form of aneurism? If this cannot 